\title{
Effect of fasting and refeeding on the consequences of myocardial infarction in rats
}

\author{
Alcione Lescano de Souza Junior ${ }^{*}$, Christiane Malfitano ${ }^{2}$, Diego Figueroa ${ }^{3}$, Leandro Eziquiel de Souza ${ }^{3}$, Eliane Ignotti ${ }^{1}$, Maria Cláudia \\ Irigoyen $^{3}$ and Rui Curi ${ }^{2}$ \\ ${ }^{1}$ Faculty of Health Sciences, University of Mato-Grosso, Cáceres, Brazil \\ ${ }^{2}$ Institute of Biomedical Sciences, University of São Paulo, Brazil \\ ${ }^{3}$ Laboratory of Hypertension, Heart Institute, São Paulo, Brazil
}

\begin{abstract}
We investigated the effects of 48 hours (h)-fasting followed by permanent coronary artery occlusion and 48 h-refeeding on the infarct size; ejection fraction; plasma creatine kinase activity; and levels of IL1- $\beta$, CINC $2 \alpha / \beta$ and IL-6, triglycerides, glycogen and ATP in the left ventricle of adult rats. Permanent coronary artery occlusion was performed in ad libitum fed (fed/fed) and 2-days-fasted rats (fasted/re-fed). After infarction induction, both groups were re-fed for $48 \mathrm{~h}$, and infarction area and ejection fraction were assessed using echocardiography. The levels of glycogen, triglyceride, ATP, and proinflammatory cytokines in the left ventricle, and the concentrations of glucose and free fatty acids in plasma were measured at the end of the 2-day fasting period. The infarct size was significantly smaller in the fasted/ re-fed group compared with the fed animals. This was accompanied by decreased plasma creatine kinase activity and improved ejection fraction. Fasting per se led to an increase in glycogen, ATP, CINC $2 \alpha / \beta$, interleukin (IL)-1 $\beta$, and IL-6, and a decrease in triacylglycerol levels in the left ventricle; along with an increase in free fatty acid concentrations and a decrease in glucose levels in the plasma. This study indicates that 2-days-fasting followed by $48 \mathrm{~h}$ refeeding protected the heart from ischemia-induced injury, which may be related to the fasting-induced metabolic condition.
\end{abstract}

\section{Introduction}

Acute myocardial infarction (AMI) is a major cause of mortality and morbidity worldwide [1]. AMI is initiated by a lack of blood flow resulting in marked reduction in the supply of oxygen and nutrients to the cardiac muscle. This in turn leads to a decrease in ATP production and causes oxidative stress, loss of ion gradient across membrane, accumulation of toxic metabolites, and inflammation [2]. Fatty acid (FA) oxidation is the main source of ATP to the heart in aerobic conditions [3,4]; however, during ischemia, ATP production occurs through anaerobic glycolysis using glucose derived from glycogen [4].

Expression of pro-inflammatory cytokines, such as IL-1 $\beta$, tumor necrosis factor (TNF)- $\alpha$, and IL- 6 , usually absent in the normal heart, is increased in the hearts of animals and humans affected by AMI $[5,6]$. The influx of inflammatory cells and production of pro-inflammatory mediators contribute to myocardial injury. However, broad inhibition of inflammation has adverse effects on outcomes following an AMI $[7,8]$. Inflammation is not an injurious process per se, since it triggers the first steps for proper AMI healing $[9,10]$.

Dietary restriction increases cardiac tolerance to ischemic injury $[11,12]$. Intermittent fasting increases capillary density [13], reduces the number of apoptotic cells, and decreases the inflammatory response in the ischemic heart [14]. A fasting period of one to three days protects from renal [15] and hepatic [16] ischemic/reperfusion injury in mice.

Nevertheless, the impact of short-term fasting followed by shortterm re-feeding on cardiac tolerance to ischemic injury, dissociated from reperfusion damage, has not been examined yet. In the present study, the infarct size, ejection fraction (EF), left ventricle (LV) mass, and levels of ATP, triglycerides (TG), glycogen and proinflammatory cytokines in the LV of rats subjected to fasting for 2 days followed by permanent coronary artery occlusion and $48 \mathrm{~h}$ re-feeding were investigated.

\section{Materials and methods}

\section{Animals and the experimental protocol}

Male Wistar rats weighing 260-280 g were obtained from the Department of Physiology and Biophysics, Institute of Biomedical Sciences, University of São Paulo. Animals were housed under a 12:12 h light-dark cycle at $23 \pm 1^{\circ} \mathrm{C}$.

The rats were randomly assigned to two experimental groups: fed ad libitum (fed/fed) or $48 \mathrm{~h}$ fasting and $48 \mathrm{~h}$ refeeding (fasted/re-fed). Six animals were used from the fed and fasted groups to evaluate the metabolic/inflammatory conditions before infarction. Animals in the fasted/re-fed group did not have access to food for $48 \mathrm{~h}$ prior to infarct induction. The animals were fed a standard laboratory chow (NUVILAB CR-1, Nuvital, Curitiba, Brazil). All groups received water ad libitum. The ethical committee of the Institute of Biomedical

Correspondence to: Alcione Lescano de Souza Junior, Faculty of Health Sciences, University of Mato-Grosso. Av. Tancredo Neves, 1095-Cavalhada II -78200-000-Cáceres-Mato Grosso- PABX +55 (65) 3221-0000, Brazil; E-mail: lescanoalcione9@gmail.com

Key words: fasting followed by refeeding, heart function, heart inflammation, heart metabolic state, infarct size, ischemic injury

Received: December 05, 2015; Accepted: December 24, 2015; Published: December 28, 2015 
Sciences of the University of São Paulo approved this study.

\section{Induction of AMI}

Surgical occlusion of the left coronary artery was performed between 5:00 pm and 7:00 pm as previously described [17-20]. Briefly, left thoracotomy was performed, the third intercostal space dissected, and the heart exposed. The left coronary artery was occluded with a single nylon (6.0) suture $1 \mathrm{~mm}$ distal to the left atrial appendage. The chest was closed using silk sutures. The animals were maintained under ventilation until recovery. All groups received standard laboratory chow and water ad libitum after surgery.

\section{Assessments of ejection fraction and infarct size}

Echocardiography was performed $48 \mathrm{~h}$ after coronary ligation, according to the guidelines of the American Society of Echocardiography. Rats were anesthetized ( $80 \mathrm{mg}$ ketamine and $12 \mathrm{mg}$ xylazine per $\mathrm{kg}$ b.w.), and images were obtained with a $10-14 \mathrm{mHz}$ linear transducer in a SEQUOIA 512 Echocardiographic System (ACUSON Corporation, Mountain View, CA, USA) for the measurement of infarct size and systolic function (ejection fraction). MI size was estimated on the basis of identification of akinetic (absence of movement), hypokinetic (decreased movement), or dyskinetic (paradoxical movement) areas $[17,18,20]$. MI size (\% of LV perimeter) was measured as the ratio of dysfunctional area to the total perimeter of the endocardial border of the LV.

\section{Cytokine levels in the LV}

ELISA Duo-set kits were used for the determination of IL- $1 \beta$, CINC- $2 \alpha / \beta$, and IL- 6 in LV protein extracts (R\&D Systems Inc., Minneapolis, MN, USA). The results were normalized by total protein levels.

\section{Measurements of ATP}

Left ventricles were dissected and stored in liquid nitrogen prior to ATP assay. The tissues were homogenized in a Polytron PT 3100 at position 3/4 (Littau-Luceme, Switzerland). Perchloric acid (0.6 $\mathrm{N})$ was used as the extraction medium and the supernatants were neutralized using $1 \mathrm{M}$ potassium bicarbonate. ATP concentrations were determined in the supernatants using an ATP determination kit (Invitrogen, Eugene, Oregon, USA). ATP contents were calculated as $\mu \mathrm{M}$ and expressed with respect to tissue wet weight.

\section{Glycogen content in the LV}

Glycogen content of the LV was determined using the method of Keppler and Decker [21]. This method is based on the conversion of glycogen into glucose by amyloglucosidase (Sigma, St. Louis. MO, USA). Glucose from glycogen was quantified using a glucose determination kit (Bioclin, Belo Horizonte, MG, Brazil). Glycogen content was calculated as $\mathrm{mg}$ of glycosyl units per gram wet weight of the LV.

\section{Triglyceride content in the LV}

For measurement of TG content in the LV, $60 \mathrm{mg}$ of frozen heart tissue was homogenized in 2:1 chloroform and methanol solution. The homogenate was centrifuged at $1,000 \mathrm{~g}$ for $20 \mathrm{~min}$ at $4^{\circ} \mathrm{C}$. The lower phase was transferred to a new tube and evaporated in a vacuum centrifuge (Vacufuge ${ }^{ø}$ plus Eppendorf). The lipid pellets were suspended in $100 \mu \mathrm{L}$ absolute ethanol. The TG content was measured by spectrophotometry using a commercial kit (Bioclin, Belo Horizonte, MG, Brazil).

\section{Glucose and free fatty acid (FFA) levels and CK activity}

Blood samples of fed and fasted/re-fed rats were collected into tubes containing EDTA through cardiac puncture. Fed rats were subjected to $6 \mathrm{~h}$ fasting before blood samples being collected. The blood samples were centrifuged at $2,000 \mathrm{rpm}$ for $15 \mathrm{~min}$ at $4^{\circ} \mathrm{C}$, and the serum was separated and frozen. Plasma CK activity and glucose concentration were determined using commercial kits (Bioclin, Belo Horizonte, MG, Brazil). Plasma FFA levels were estimated as reported by Falholt et al. [22].

\section{Statistical analysis}

Results are presented as mean \pm SEM. Student's $t$ test was used for comparison between the two groups: fed/fed vs. fasted/re-fed and fed vs. fasted. Differences between values were considered statistically significant at $\mathrm{p}<0.05$. All results were analyzed using the GraphPad Prism 5.0 statistical software (GraphPad Software, San Diego, CA, USA).

\section{Results}

The body weight of the fed/fed group remained unchanged during the $96 \mathrm{~h}$ of experiment. However, the body weight of fasted/ re-fed animals was decreased (by 19\%) after $48 \mathrm{~h}$ fasting but remained unchanged afterwards (Figure 1).

\section{Before myocardial infarction}

Plasma glucose levels in the fasted group were $37 \%$ lower, whereas plasma FFA concentrations were increased 2-fold due to fasting for $48 \mathrm{~h}$ (Table 1). The ATP concentration was 33\% higher, whereas the glycogen content was 4 -fold higher in the LV of the fasted compared with the fed group (Figures 2A-2B). The TG content in the LV of hearts from fasted rats was $61 \%$ lower compared with the fed group (Figure 2C).

The levels of CINC-2 $\alpha / \beta$, IL-1 $\beta$, and IL-6 were higher (by 3.2-, 4.9-, and 1.4-fold, respectively) in the fasting compared with the fed group (Figures 3A-3C).

\section{After myocardial infarction}

The size of the infarct, measured using echocardiography $48 \mathrm{~h}$ after ischemia induction, was $37 \%$ smaller in fasted/re-fed rats compared with the fed/fed group (Figure $4 \mathrm{~A}$ ). In addition, the ejection fraction was $31 \%$ higher in the fasted/re-fed compared with the fed/fed group (Figure 4B). Plasma CK activity was lower in the fasted/re-fed compared with the fed/fed group (Figure 5A). Similarly, the LV/heart weight ratio was decreased in the fed/fed compared with the fasted/ re-fed animals (Figure 5B). The levels of CINC- $2 \alpha / \beta$, IL- $1 \beta$, and IL-6 in the LV (Figures 6A-6C) and the plasma FFA levels (Figure 7) were not different among the groups.

\section{Discussion}

The key finding of this study was that fasting for $48 \mathrm{~h}$ prior to the induction of infarction followed by refeeding limited the extent of the infarcted area and prevented the expected systolic dysfunction

\begin{tabular}{|l|l|c|}
\hline \multicolumn{1}{|l|}{} & Fed & Fasted \\
\hline Glucose $(\mathrm{mg} / \mathrm{dL})$ & $113.6 \pm 3.26$ & $71.40 \pm 3.61 * *$ \\
\hline Free fatty acids $(\mathrm{mM})$ & $0.32 \pm 0.017$ & $0.62 \pm 0.072 * *$ \\
\hline
\end{tabular}

Values are expressed as mean \pm SEM. ${ }^{* *} P<0.01$ vs the fed group.

Table 1. Plasma glucose and free fatty acid concentrations in the ad libitum fed (fed) and $48 \mathrm{~h}$ fasted (fasted) groups before infarct induction. 
Body weight

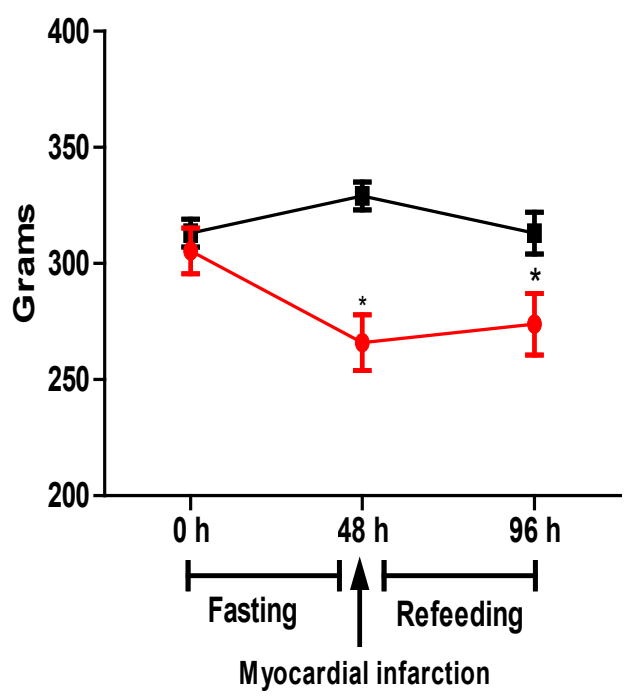

Figure 1. Body weight (g) before (48 h) and after $(96 \mathrm{~h})$ infarct induction in fed/fed and fasted/re-fed rats. Values are expressed as mean \pm SEM of six rats per group. ( $P<0.05)$ compared with the zero hour period.
$2 \mathrm{~A}$

ATP

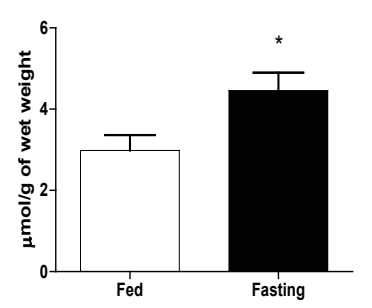

$2 B$

Glycogen

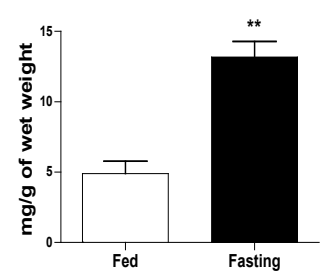

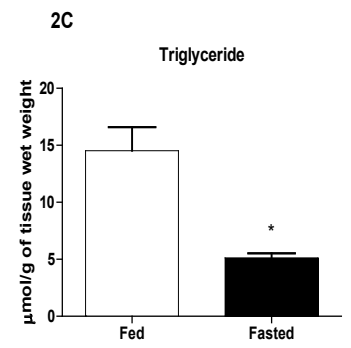

Figure 2. Contents of ATP (A), glycogen (B), and TG (C) in the left ventricle before infarct induction. The following groups were studied: Fed ad libitum (Fed) and $48 \mathrm{~h}$ fasted (Fasted). Values are expressed as mean \pm SEM of six animals per group. ${ }^{*} P<0.05 ;{ }^{* *} P<$ 0.01 compared with the Fed group.

partially. Additionally, fasting for $48 \mathrm{~h}$ per se led to an increase in the levels of ATP, glycogen, CINC- $2 \alpha / \beta$, IL- $1 \beta$, and IL- 6 , and a reduction in the TG levels, in the LV.

Consistent with our observations, Snorek et al. [23] demonstrated that three-day fasting effectively reduces infarct size and ventricular arrhythmias under ischemia/reperfusion. Within $24 \mathrm{~h}$ after coronary ligation, death by necrosis is the primary cause of cardiomyocyte loss [24]. The reduced infarct size observed here reflects the protective effect of fasting on necrosis, as suggested by the lower plasma CK activity and

preservation of the LV mass after infarction.

The mechanism mediating the cardioprotection induced by fasting/refeeding remains to be fully elucidated. However, the increase in glycogen content in the heart before infarction possibly plays an important role. In the isolated heart experimental model, glycogen
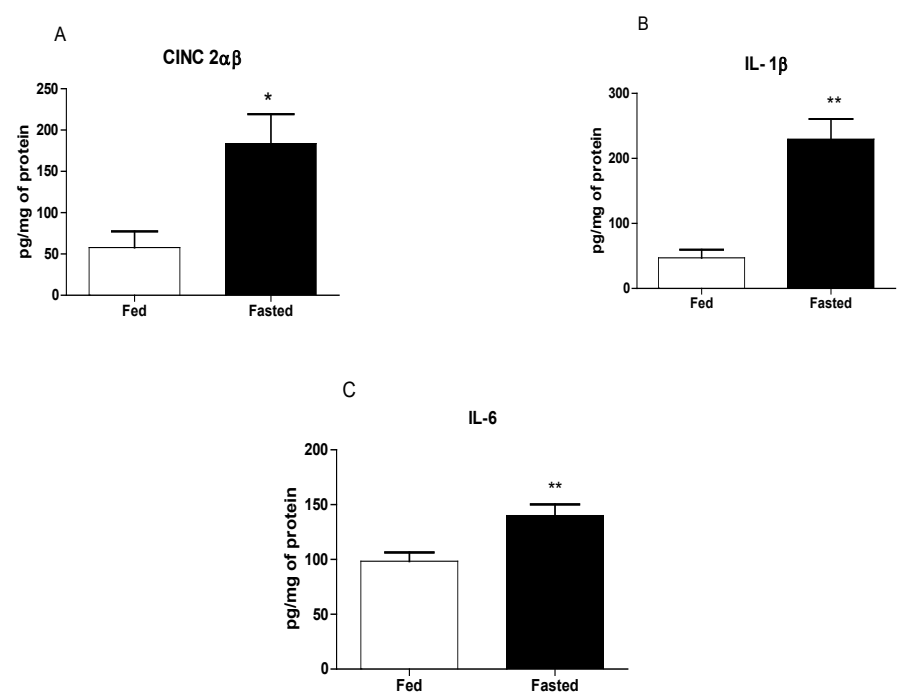

Figure 3. Levels of CINC- $2 \alpha / \beta$, IL- $1 \beta$, and IL- 6 in the left ventricle before infarction. The following groups were studied: Fed ad libitum (Fed) and $48 \mathrm{~h}$ fasted (Fasted). Values are expressed as mean \pm SEM of six animals per group. ${ }^{*} P<0.05$; ${ }^{* *} P<0.01$ compared with the Fed group.
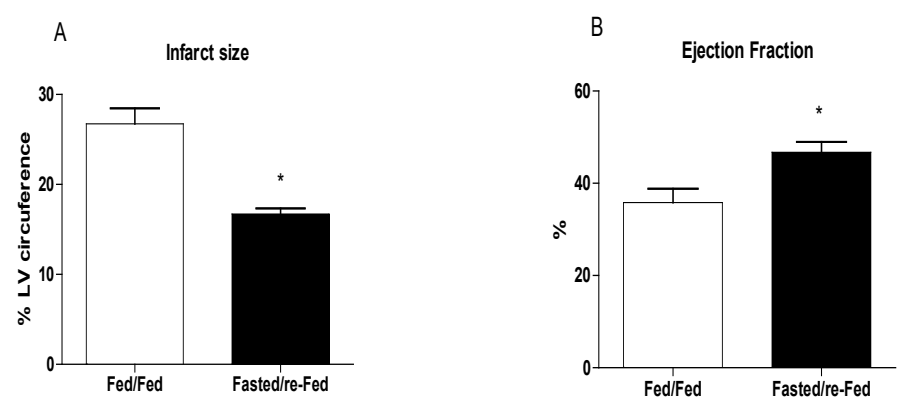

Figure 4. Infarct size and ejection fraction $48 \mathrm{~h}$ after infarct induction. The following groups were studied: Fed ad libitum (Fed/Fed) and $48 \mathrm{~h}$ fasting/re-feeding (Fasted/reFed). Values are expressed as mean \pm SEM of at least seven animals per group. ${ }^{\text {}} P<0.05$ compared with the Fed/Fed group.

A

Plasma creatine kinase activity

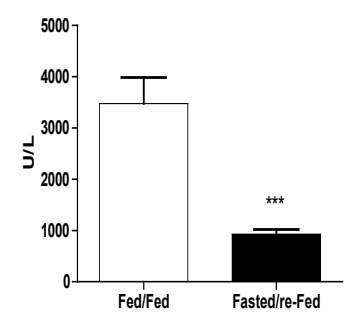

Figure 5. Creatine kinase activity in plasma and LV/heart weight ratio $48 \mathrm{~h}$ after infarct induction. The following groups were studied: Fed ad libitum (Fed/Fed) and $48 \mathrm{~h}$ fasting/ re-feeding (Fasted/re-Fed). Values are expressed as mean \pm SEM of at least six animals per group. ${ }^{* * * *} P<0.001$ compared with the Fed/Fed group. 

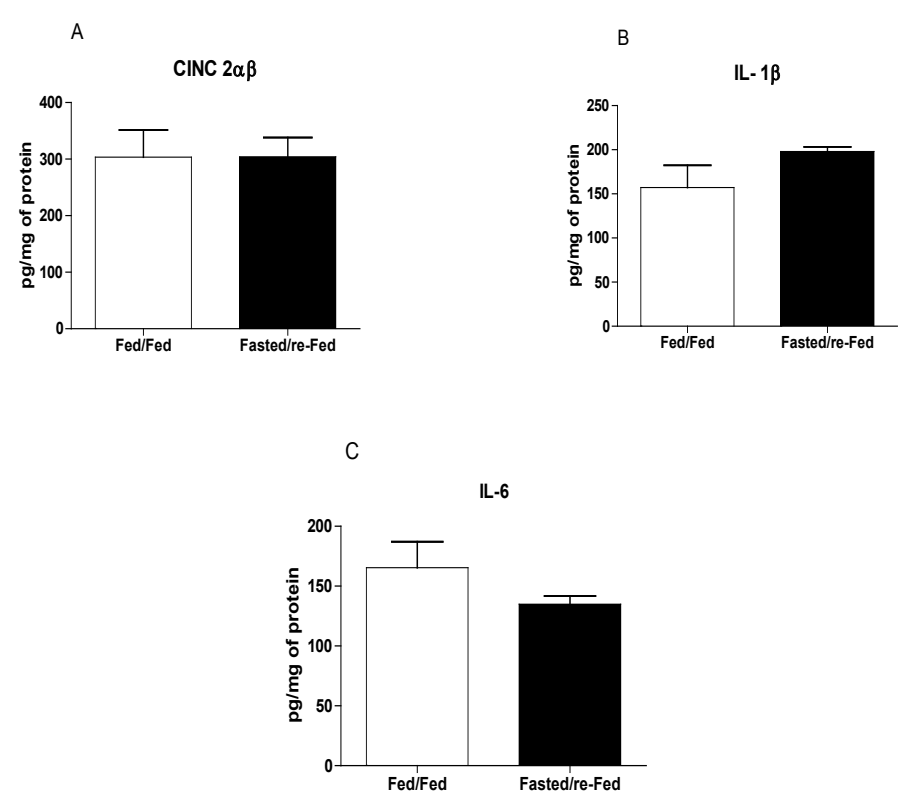

Figure 6. Levels of CINC- $2 \alpha / \beta$, IL-1 $\beta$, and IL-6 in the left ventricle $48 \mathrm{~h}$ after infarct induction. The following groups were studied: Fed ad libitum (Fed/Fed) and $48 \mathrm{~h}$ fasted re-fed. Values are expressed as mean \pm SEM of six animals per group.

\section{Plasma Free Fatty acid}

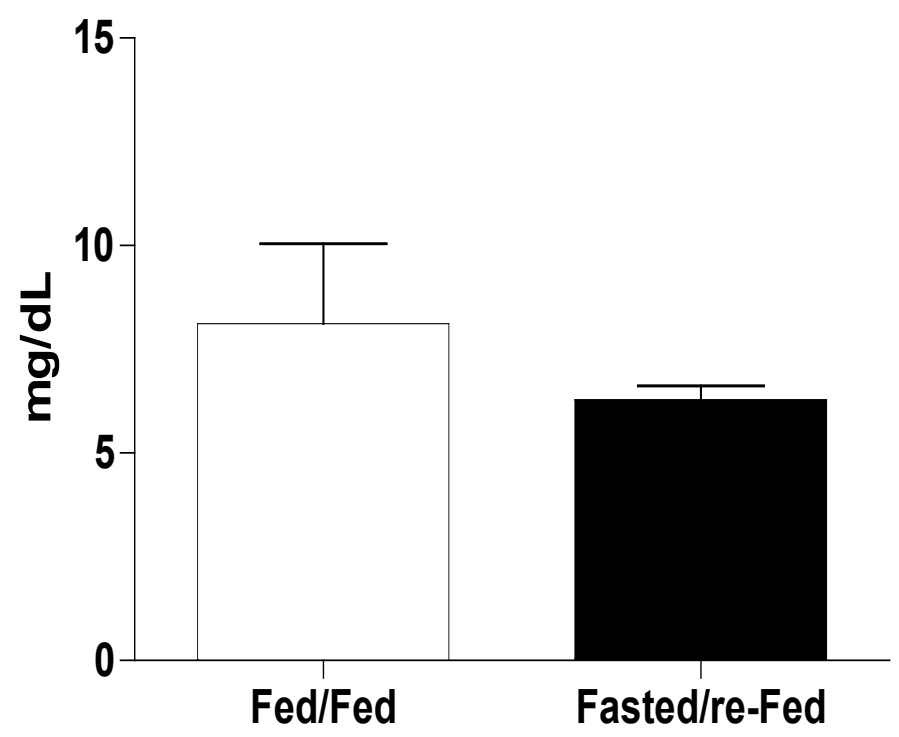

Figure 7. Free fatty acid concentrations in plasma $48 \mathrm{~h}$ after infarct induction. The following groups were studied: Fed ad libitum (Fed/Fed) and $48 \mathrm{~h}$ Fasted/re-Fed. Values are expressed as mean \pm SEM of seven animals per group.

accumulation, induced by fasting or insulin administration, has been shown to increase ATP and ADP levels, normalize glucose utilization, reduce cardiomyocyte membrane damage, and shorten recovery time after ischemia [25]. Here, we showed that fasting for $48 \mathrm{~h}$ followed by permanent coronary artery occlusion and $48 \mathrm{~h}$ re-feeding is an effective protocol to protect the heart from ischemic injury.

Kokubun et al. [26] showed that fasting for $12 \mathrm{~h}$ and $48 \mathrm{~h}$ leads to an increase in the glycogen content of the heart, while reducing the glycogen content in the skeletal muscle and liver in rats. Randle et al. [27] postulated that increased plasma FFA concentrations reduce glucose utilization and lead to glycogen accumulation in the heart. Suzuki et al. [28] reported that serum FFA concentrations increase two-fold in $16 \mathrm{~h}$ - and $48 \mathrm{~h}$-fasted mice. A two-fold increase in plasma FFA concentrations was also observed in our study after fasting for $48 \mathrm{~h}$. FFAs are used preferentially as fuels in aerobiosis and account for $60-90 \%$ of the ATP produced in the heart under non-ischemic conditions $[3,4]$. In the present study, the decrease in TG levels in the $\mathrm{LV}$ of animals fasted for $48 \mathrm{~h}$ point to an increase in FA oxidation before infarction induction. This was associated with an increase in ATP content. However, under anaerobic conditions, FA oxidation is decreased and ATP production is dependent on anaerobic utilization of glucose derived from glycogen degradation $[4,26]$.

Cell survival following acute myocardial ischemia requires marked changes in metabolism in the heart. Goodwin et al. [29] showed that under adrenergic stimulation, glucose uptake by the perfused heart is delayed in relation to the burst of glycogenolysis, indicating the important role of glycogen in stress conditions. Therefore, increased levels of FFAs in the plasma, and of ATP and glycogen in the LV after $48 \mathrm{~h}$-fasting are part of the adaptive metabolic changes that protect the heart from an infarct-induced injury.

Liepinsh et al. [30] reported an increase in the infarct size in ex vivo perfused heart from fasted compared with fed rats. This effect was observed immediately post-reperfusion in the ischemia/reperfusion model. They used a Krebs-Henseleit buffer solution supplemented with metabolites for reperfusion to mimic the blood plasma parameters found in the fasted state. In the fasted state, plasma concentrations of FFA are elevated [28]. FA oxidation overrides glucose oxidation, which decreases the contribution of anaerobic glycolysis to energy production in the myocardium. The differences between our study and that of Liepinsh et al. may be explained by the fact that we measured the infarcted area after $48 \mathrm{~h}$ of refeeding, when the plasma fatty acid concentrations were not elevated. Hence, the elevated plasma FFA levels in the fasting state are necessary for metabolic changes (increase in glycogen and ATP in LV), but may be detrimental in MI condition; impairing glucose metabolism if permanently elevated. Malfitano et al. [20] demonstrated cardioprotection from ischemia injury in streptozotocin-induced diabetic rats after two weeks of tissue remodeling. Like in the fasting, they showed that the diabetic condition per se increased glycogen in the LV and FFA plasma concentration before infarct induction and, under low plasma and tissue FFA concentrations, systolic dysfunction and infarct size were smaller when compared with non-diabetic animals. Furthermore, previous studies, using ex vivo isolated perfused hearts, concluded that hearts from fasted rats are better protected from injury induced by ischemia/ reperfusion $[26,31,32]$; these results are in agreement with our findings. These studies used buffer solution for perfusion that closely mimics the fed state with low plasma FFA levels.

We found increased amounts of CINC- $2 \alpha / \beta$, IL- $1 \beta$, and IL- 6 in the LV from the fasted group before MI induction. Verweij et al. [16] reported that the increased mRNA expression of IL-6 and P-selectin played a protective role against ischemia/reperfusion injury in the liver of 3-day-fasted mice.

Excess plasma FFAs can be harmful to cardiac tissue [33]. Zhou et al. [34] demonstrated that cardiac dysfunction in obesity is caused by apoptosis of cadiomiocytes due to exposure to high FFA levels. Under fed conditions, FAs are mainly derived from the hydrolysis of 
TG-rich lipoproteins on the endothelial surface of coronary arteries. During fasting, reduced glucose utilization triggers FA release from the heart TG, leading to FA supply far beyond the oxidation capacity of the tissue. This excess of FFAs causes cell death that has been defined as "cardiac lipotoxicity" [35]. This is likely the mechanism by which fasting for $48 \mathrm{~h}$ causes inflammation in the LV. In the fasting state, cardiomyocytes are exposed to high plasma FFA concentrations and to FFAs from the heart TG stores.

The metabolic changes (glycogen and ATP accumulation and intense TG mobilization) induced by $48 \mathrm{~h}$ fasting put the heart in an "alert" state, as indicated by increased CINC- $2 \alpha / \beta$, IL- $1 \beta$, and IL- 6 levels in the LV, to deal with eventual injury episodes. The smaller infarct size and normal ejection fraction observed in the fasted/re-fed group may be a consequence of the metabolic adaptation imposed by fasting.

\section{Acknowledgements}

The authors are grateful to J.R. Mendonça and to Dr. Tatiana Carolina Alba Loureiro for excellent technical assistance.

\section{Author contributions}

A.L.S.J., M.C.I., and R.C. designed the experiments. A.L.S.J., C.M., D.F., and L.E.S. performed the experiments. A.L.S.J., M.C.I., and RC analyzed and interpreted the data. The article was revised by M.C.I. and R.C. A.L.S.J. and E.I. wrote the manuscript. All authors read and approved the final version of the manuscript.

\section{Funding}

This study was supported by Conselho Nacional de Desenvolvimento Científico e Tecnológico (CNPq), Coordenação de Aperfeiçoamento de Pessoal de Nível Superior (CAPES), Fundação de Amparo à Pesquisa do Estado de São Paulo (FAPESP), and the Guggenheim Foundation.

\section{Conflict of interest}

The author(s) declare that they have no conflicts of interest.

\section{References}

1. WHO - World Health Organization (2011) Cardiovascular Disease and Control: Missed Opportunities.

2. Chiong M, Wang ZV, Pedrozo Z, Cao DJ, Troncoso R, et al. (2011) Cardiomyocyte death: mechanisms and translational implications. Cell Death Dis 2: e244. [Crossref]

3. van der Vusse GJ, van Bilsen M, Glatz JF (2000) Cardiac fatty acid uptake and transport in health and disease. Cardiovasc Res 45: 279-293. [Crossref]

4. Abozguia K, Shivu GN, Ahmed I, Phan TT, Frenneaux MP (2009) The heart metabolism: pathophysiological aspects in ischaemia and heart failure. Curr Pharm Des 15: 827-835. [Crossref]

5. Frangogiannis NG (2006) Targeting the inflammatory response in healing myocardial infarcts. Curr Med Chem 13: 1877-1893. [Crossref]

6. Timmers L, Pasterkamp G, de Hoog VC, Arslan F, Appelman Y, et al. (2012) The innate immune response in reperfused myocardium. Cardiovasc Res 94: 276-283. [Crossref]

7. Silverman HS, Pfeifer MP (1987) Relation between use of anti-inflammatory agents and left ventricular free wall rupture during acute myocardial infarction. Am J Cardiol 59: 363-364. [Crossref]

8. Brown EJ Jr, Kloner RA, Schoen FJ, Hammerman H, Hale S, et al. (1983) Scar thinning due to ibuprofen administration after experimental myocardial infarction. Am J Cardiol 51: 877-883. [Crossref]

9. Frangogiannis NG (2014) The immune system and the remodeling infarcted heart: cell biological insights and therapeutic opportunities. J Cardiovasc Pharmacol 63: 185195. [Crossref]
10. Shinde AV, Frangogiannis NG2 (2014) Fibroblasts in myocardial infarction: a role in inflammation and repair. J Mol Cell Cardiol 70: 74-82. [Crossref]

11. Broderick TL, Belke T, Driedzic WR (2002) Effects of chronic caloric restriction on mitochondrial respiration in the ischemic reperfused rat heart. Mol Cell Biochem 233: 119-125. [Crossref]

12. Ahmet I, Tae HJ, de Cabo R, Lakatta EG, Talan MI (2011) Effects of calorie restriction on cardioprotection and cardiovascular health. J Mol Cell Cardiol 51: 263-271. [Crossref]

13. Katare RG, Kakinuma Y, Arikawa M, Yamasaki F, Sato T (2009) Chronic intermittent fasting improves the survival following large myocardial ischemia by activation of BDNF/VEGF/PI3K signaling pathway. J Mol Cell Cardiol 46: 405-412. [Crossref]

14. Wan R, Ahmet I, Brown M, Cheng A, Kamimura N, et al. (2010) Cardioprotective effect of intermittent fasting is associated with an elevation of adiponectin levels in rats. J Nutr Biochem 21: 413-417. [Crossref]

15. Mitchell JR, Verweij M, Brand K, van de Ven M, Goemaere N, et al. (2010) Short-term dietary restriction and fasting precondition against ischemia reperfusion injury in mice. Aging Cell 9: 40-53. [Crossref]

16. V Verweij M, van Ginhoven TM, Mitchell JR, Sluiter W, van den Engel S, et al (2011) Preoperative fasting protects mice against hepatic ischemia/reperfusion injury: mechanisms and effects on liver regeneration. Liver Transpl 17: 695-704. [Crossref]

17. Malfitano C, Alba Loureiro TC, Rodrigues B, Sirvente R, Salemi VM, et al. (2010) Hyperglycaemia protects the heart after myocardial infarction: aspects of programmed cell survival and cell death. Eur J Heart Fail 12: 659-667. [Crossref]

18. Mostarda C, Rodrigues B, Medeiros A, Moreira ED, Moraes-Silva IC, et al. (2014) Baroreflex deficiency induces additional impairment of vagal tone, diastolic function and calcium handling proteins after myocardial infarction. Am J Transl Res 6: 320-328 [Crossref]

19. Rodrigues B, Jorge L, Mostarda CT, Rosa KT, Medeiros A, et al. (2012) Aerobic exercise training delays cardiac dysfunction and improves autonomic control of circulation in diabetic rats undergoing myocardial infarction. J Card Fail 18: 734-744. [Crossref]

20. Malfitano C, de Souza Jr AL, Carbonaro M, Bolsoni-Lopes A, Figueroa D, et al. (2015) Glucose and fatty acid metabolism in infarcted heart from streptozotocin-induced diabetic rats after 2 weeks of tissue remodeling. Cardiovasc Diabetol 14(1): 149. [Crossref]

21. Kepler D, Decker K (1974) Glycogen Determination with Amyloglucosidase. In Bergmeyer HU, editor. Methods of Enzymatic Analyses. 4th ed. Weinheim; Verlag Chemie 3: 1127-1131.

22. Falholt K, Lund B, Falholt W (1973) An easy colorimetric micromethod for routine determination of free fatty acids in plasma. Clin Chim Acta 46: 105-111. [Crossref]

23. Snorek M, Hodyc D, Sedivý V, Durišová J, Skoumalová A, et al. (2012) Short-term fasting reduces the extent of myocardial infarction and incidence of reperfusion arrhythmias in rats. Physiol Res 61: 567-574. [Crossref]

24. Bartling B, Holtz J, Darmer D (1998) Contribution of myocyte apoptosis to myocardial infarction? Basic Res Cardiol 93: 71-84. [Crossref]

25. Schneider CA, Taegtmeyer H (1991) Fasting in vivo delays myocardial cell damage after brief periods of ischemia in the isolated working rat heart. Circ Res 68: 10451050. [Crossref]

26. Kokubun E, Hirabara SM, Fiamoncini J, Curi R, Haebisch H (2009) Changes of glycogen content in liver, skeletal muscle, and heart from fasted rats. Cell Biochem Funct 27: 488-495. [Crossref]

27. Randle PJ, Garland PB, Hales CN, Newsholme EA (1963) The glucose fatty-acid cycle. Its role in insulin sensitivity and the metabolic disturbances of diabetes mellitus. Lancet 1(7285): 785-789. [Crossref]

28. Suzuki J, Shen WJ, Nelson BD, Selwood SP, Murphy GM Jr, et al. (2002) Cardiac gene expression profile and lipid accumulation in response to starvation. Am J Physiol Endocrinol Metab 283: E94-94E102. [Crossref]

29. Goodwin GW, Ahmad F, Doenst T, Taegtmeyer H (1998) Energy provision from glycogen, glucose, and fatty acids on adrenergic stimulation of isolated working rat hearts. Am J Physiol 274: H1239-1247. [Crossref]

30. Liepinsh E, Makrecka M, Kuka J, Makarova E, Vilskersts R, et al. (2014) The heart is better protected against myocardial infarction in the fed state compared to the fasted state. Metabolism 63: 127-136. [Crossref] 
31. Doenst T, Guthrie PH, Chemnitius JM, Zech R, Taegtmeyer H (1996) Fasting, lactate, and insulin improve ischemia tolerance in rat heart: a comparison with ischemic preconditioning. Am J Physiol 270: H1607-1615. [Crossref]

32. Schaefer S, Ramasamy R (1997) Glycogen utilization and ischemic injury in the isolated rat heart. Cardiovasc Res 35: 90-98. [Crossref]

33. Sharma S, Adrogue JV, Golfman L, Uray I, Lemm J, et al. (2004) Intramyocardial lipid accumulation in the failing human heart resembles the lipotoxic rat heart. FASEB $J 18$ : 1692-1700. [Crossref]

34. Zhou YT, Grayburn P, Karim A, Shimabukuro M, Higa M, et al. (2000) Lipotoxic heart disease in obese rats: implications for human obesity. Proc Natl Acad Sci U S A 97 1784-1789. [Crossref]

35. Chavez, J.A., Summers, S.A., (2010) Lipid oversupply, selective insulin resistance, and lipotoxicity: molecular mechanisms. Biochim Biophys Acta 1801: 252-265. [Crossref]

Copyright: $(02015$ Souza Junior AL. This is an open-access article distributed under the terms of the Creative Commons Attribution License, which permits unrestricted use, distribution, and reproduction in any medium, provided the original author and source are credited. 